\title{
Value of the oral swab for the molecular diagnosis of dogs in different stages of infection with Leishmania infantum
}

\author{
Mariana Aschar ${ }^{\mathrm{a}}$, Eveline Tozzi Braga de Oliveira ${ }^{\mathrm{b}}$, Marcia Dalastra Laurenti ${ }^{\mathrm{a}}$, \\ Mary Marcondes ${ }^{b}$, Jose Eduardo Tolezano ${ }^{c}$, Roberto Mitsuyoshi Hiramoto ${ }^{c}$, \\ Carlos Eduardo P. Corbett ${ }^{\mathrm{a}}$, Vania Lucia Ribeiro da Matta ${ }^{\mathrm{a}, *}$ \\ a Laboratory of Pathology of Infectious Diseases (LIM50), Medical School, University of São Paulo, São Paulo, SP, Brazil \\ ${ }^{\mathrm{b}}$ Department of Clinics, Veterinary School, UNESP, Araçatuba, SP, Brazil

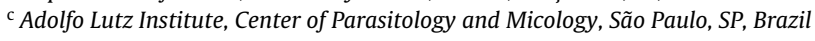

\section{A R T I C L E I N F O}

\section{Article history:}

Received 23 November 2015

Received in revised form 1 June 2016

Accepted 2 June 2016

\section{Keywords:}

Oral swab

Conjunctival swab

Leishmania infantum

Canine visceral leishmaniasis

Molecular diagnosis

Apparently healthy infected dogs

Sick dogs

\begin{abstract}
A B S T R A C T
This study was based on the need to employ a sensitive and specific method with samples that could be easily collected for diagnosing dogs infected with Leishmania infantum. To this end, we used real time-PCR (qPCR) to assess the value of the oral swab (OS) in detecting infected sick dogs (SD; $n=62$ ), including, for the first time, the analysis of apparently healthy infected dogs ( $A D ; n=30)$, both from endemic areas for visceral leishmaniasis (VL). For comparison, we also evaluated the performance of the conjunctival swab (CS), blood (BL), lymph node (LN) and serology. We detected the presence of Leishmania DNA in the oral cavity in 62 out of the 92 dogs studied. The OS positivity (67.4\%) was equivalent to the CS (68.5\%) $(\mathrm{p}>0.05)$, higher than BL $(52.2 \%)(\mathrm{p} \leq 0.05)$, and lower than LN $(84.8 \%)(\mathrm{p} \leq 0.05)$. OS and CS performed well in SD dogs (82.3\% and 83.9\%, respectively) but not in AD dogs (36.7\% for both samples). BL showed the lowest positivity (52.2\%) and provided equivalent results between AD (60.0\%) and SD (48.4\%) dogs $(p>0.05)$. LN yielded the highest positivity (84.8\%), and it was also higher in the SD population (93.5\%) compared to the AD population $(66.7 \%)(\mathrm{p} \leq 0.05)$. Parasite load was high in $\mathrm{LN}$, moderate in OS and CS, and low in BL, showing the relationship between the levels of parasitism and the positivity rates found in these samples. Serology was positive in $82.2 \%$ of the SD group and in $70 \%$ of the AD dogs $(p>0.05)$. Among the 20 seronegative dogs, seven (35\%) were positive in either OS or CS, and 12 (60\%) were positive when both noninvasive samples were jointly considered. The OS/CS combination resulted in a significant increase of positivity ( $\mathrm{p} \leq 0.05$ ) for the AD dogs (from $36.7 \%$ to $63.4 \%$ ), as well as OS/serology ( $80 \%$ ) and OS/CS/serology (83.4\%). For the SD population, positivity reached up to $95.2 \%$ with the same combinations, showing that combination of samples and/or tests is required for the identification of dogs infected with L. infantum and that the OS and CS combination based on qPCR notably improves the detection of both $\mathrm{AD}$ and SD dogs.

In conclusion, OS proved to be a suitable sample for the molecular diagnosis of infected dogs with clinical signs of VL, but not for dogs with inapparent infection. For these, we recommend the combination of OS results with CS and/or serology in order to reach relevant positivity for L. infantum. Finally, another advantage of using OS or both noninvasive samples is the increased likelihood of diagnosing seronegative dogs.
\end{abstract}

(C) 2016 Elsevier B.V. All rights reserved.

\section{Introduction}

Visceral leishmaniasis (VL) is a neglected vector-borne tropical disease that is endemic in 65 countries, including Brazil. The

\footnotetext{
* Corresponding author.

E-mail address: mattav@usp.br (V.L.R. da Matta).
}

zoonotic disease is caused by the intracellular protozoan parasite Leishmania infantum (syn Leishmania chagasi) that is mainly transmitted by Lutzomyia longipalpis in the New World (WHO, 2011; Alvar et al., 2012).

VL can affect humans, as well as both wild and domestic animals. Dogs (Canis familiaris) are the main reservoir in urban areas, and have been responsible for dispersing the disease in endemic regions (Michalsky et al., 2007; Laurenti et al., 2013). From the per- 
spective of human risk, canine visceral leishmaniasis (CVL) must be taken into account, given that canine disease usually precedes the emergence of human cases, and a clear correlation between canine and human infection rates has been demonstrated (Werneck et al., 2007; Falqueto et al., 2009).

Brazil accounts for up to $90 \%$ of all cases in Latin America, recording 3500 cases per year (Alvar et al., 2012), and canine infection can be as high as $57 \%$ in some endemic areas (Falqueto et al., 2009), which shows the public health problem VL represents in Brazil. Measures such as the early diagnosis and treatment of human cases, control of vectors, health education, and the culling of seropositive dogs are advocated to control the spread of VL (Romero and Boelaert, 2010)

The infection of dogs can be inapparent or present with a wide range of clinical signs that can overlap with other canine diseases, making the diagnosis of CVL challenging (Gomes et al., 2008). The canine diagnosis is based on clinical manifestations as well as on laboratorial tests to confirm the disease in dogs suspected to be ill or to investigate infection in apparently healthy dogs (Miró et al., 2008). Serology is by far the most widely used for this purpose, especially in surveys carried out in endemic areas, but it does not fully discriminate dogs infected with $L$. infantum from those with other diseases (do Rosário et al., 2005; Zanette et al., 2014; Laranjeira et al., 2014; Laurenti et al., 2014), as it fails to detect a portion of animals with subclinical infection (Porrozzi et al., 2007), and dogs vaccinated against leishmaniasis from those naturally infected (Marcondes et al., 2013). The insufficient accuracy of serological assays has caused the euthanasia of false-positive animals and, conversely, the maintenance of false-negative dogs in transmission areas, increasing risk to humans by the transmission route dog-sand fly-human (Bevilacqua and Alves, 2004; Laurenti et al., 2013).

Parasitological diagnosis is definitive and can be accomplished by direct observation of Leishmania amastigotes in lymphoid tissues or, less frequently, by immunohistochemistry (IHC) or parasite isolation (Grimaldi and Tesh, 1993; Xavier et al., 2006; Moreira et al., 2007). All these methods are carried out on invasive samples, are time-consuming and impracticable to be performed on a large scale. On the other hand, molecular tools have become increasingly prominent in detecting Leishmania infection due to their notable sensitivity, specificity, and flexibility in choice of samples (Srividya et al., 2012). Several studies have confirmed PCR's superior performance when compared with direct exam, IHC and serology (Moreira et al., 2007; Quaresma et al., 2009; Santos et al., 2014). Others point out the advantage of using the real-time PCR (qPCR) format, especially when based on multicopy targets, such as the Leishmania kinetoplast DNA (kDNA) (de Paiva Cavalcanti et al., 2009; Reis et al., 2013).

One of the limiting factors of using a diagnostic technique on a large scale is the collection of the clinical material, which ideally should be quick, simple, and painless. Thus, the association of PCR with noninvasive samples could represent an important contribution to the diagnosis of CVL.

Results are encouraging with the use of the conjunctival swab in the molecular diagnosis of infected dogs (Francino et al., 2006; Leite et al., 2010; de Almeida Ferreira et al., 2012; Di Muccio et al., 2012; Lombardo et al., 2012; Leite et al., 2015). Nevertheless, many animals reject the conjunctival scraping, and the cornea could be damaged during the procedure.

The oral swab is a practical solution for sample collection and does not cause any harm to the patient. Recently, Lombardo et al. (2012) demonstrated Leishmania DNA in canine oral mucosa for the first time, and de Ferreira et al. (2013) showed its potential use in sick dogs. Following in this direction, the aim of the present study was to evaluate the oral swab as an alternative sample for the molecular diagnosis of $L$. infantum infection, including, for the first time, apparently healthy infected dogs that represent the most prevalent population in VL-endemic areas, for which serological and parasitological diagnoses may fail. In the current study, we used a potent diagnostic tool, qPCR targeting Leishmania kDNA, and compared the oral swab performance with that of the conjunctival swab, lymph node, blood and serology, considering clinical groups (dogs with inapparent infection and sick dogs), parasite load, and combined results of the oral swab with the other samples and serology.

\section{Material and methods}

\subsection{Ethics statement}

This study was approved by the Ethics Committee for the use of Animals in Research of the Medical School- University of São Paulo, under the protocol no. 375/12. All procedures were conducted in accordance with the guidelines of the Brazilian College of Animal Experimentation (COBEA) and with the Brazilian Federal Law 11.794/08.

\subsection{Population and areas of the study}

We investigated adult mongrel dogs with different ages and gender referred to the Centers for Zoonosis Control of Araçatuba $\left(21^{\circ} 12^{\prime} 32^{\prime \prime} \mathrm{S}, 50^{\circ} 25^{\prime} 58^{\prime \prime} \mathrm{W}\right)$, Andradina $\left(20^{\circ} 53^{\prime} 45^{\prime \prime} \mathrm{S}, 51^{\circ} 22^{\prime} 44^{\prime \prime} \mathrm{W}\right)$,

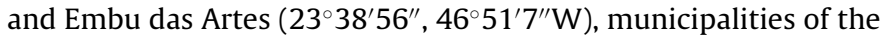
São Paulo State (Brazil) where CVL is endemic. In those places, we selected dogs presenting clinical signs compatible with CVL. Apparently healthy dogs were obtained in private clinics from the same regions above mentioned. Those with proven infection ( $n=92$ dogs), i.e, with positive molecular diagnosis at least in one of the samples studied (section 2.2) were enrolled in the study and assorted into two groups, one composed of 30 apparently healthy infected dogs (AD), and another with 62 sick dogs (SD). The signs found in SD group were lymphadenomegaly and/or splenomegaly $(79.0 \%, 49 / 62)$, dry exfoliative dermatitis and/or ulcers, $(69 \%, 43 / 62)$, ocular signs $(58.1 \%, 36 / 62)$, onychogryphosis (40.3\%, 25/62), diffuse alopecia (33.9\%, 21/62), and epistaxis (4.8\%, $3 / 62)$.

\subsection{Clinical samples}

Peripheral blood (BL) was collected from venous punctures for qPCR, and serological tests. All samples were stored at $-20^{\circ} \mathrm{C}$ until use. Exfoliative cells from oral cavity and conjunctiva were collected with rayon sterile swabs (Inlab, Brazil). The oral swab (OS) was firmly scraped against the right and left sides of the oral cavity, including the gums, and the conjunctival swab(CS) was scraped against the lower eyelid of both eyes. The tips were broken into sterile microtubes containing $200 \mu \mathrm{L}$ of preservation NET buffer $(0.15 \mathrm{M}$ $\mathrm{NaCl}, 50 \mathrm{mM}$ EDTA, $0.1 \mathrm{M}$ Tris- $\mathrm{HCl}, \mathrm{pH} 7.5)$ and kept them at $4{ }^{\circ} \mathrm{C}$ until use. The lymph node aspirate (LN) was collected from cervical or popliteal region (the most palpable) with a $10 \mathrm{~mL}$ syringe and $25 \times 7 \mathrm{~mm}$ needle. The material was transferred to sterile microtubes containing $200 \mu \mathrm{L}$ of preservation NET buffer and stored at $4{ }^{\circ} \mathrm{C}$ until use.

\subsection{Serological tests}

DPP $^{\circledR}\left(\right.$ DPP $^{\circledR}$ CVL rapid test, BioManguinhos, Rio de Janeiro, Brazil) was performed according to the manufacturer's recommendations and the results were interpreted visually (Grimaldi et al., 2012). Enzyme-immunoassay (EIE ${ }^{\circledR}$ Bio-Manguinhos, Rio de Janeiro, Brazil) was developed according to the manufacturer's recommendations. The optical densities (OD) were evaluated with the 
wavelength of $450 \mathrm{~nm}$, using a spectrophotometer (Laurenti et al., 2014).

\subsection{DNA extraction}

The DNA extraction of OS, CS, and LN was performed using the NucleoSpin ${ }^{\circledR}$ Tissue kit (Macherey-Nagel, Germany), according to the manufacturer's recommendations. The DNA extraction from BL was performed with the Illustra Blood Genomic Mini Prep (GE Healthcare, USA), following the kit protocol. The DNA was stored at $-20^{\circ} \mathrm{C}$ until use.

\subsection{Real time $P C R(q P C R)$}

We used primers targeting conserved regions of Leishmania kDNA, LEISH-1 (5'-AACTTTTCTGGTCCTCCGGGTAG-3') and LEISH-2 (5'-ACCCCCAGTTTCCCGCC-3') (Francino et al., 2006). The amplification was performed in a final volume of $15 \mu \mathrm{L}$ that consisted of $5 \mu \mathrm{L}$ of total DNA set at $10 \mathrm{ng} / \mu \mathrm{L}, 7.5 \mu \mathrm{L}$ of Kapa SYBR Fast Universal $2 \times$ qPCR Master Mix (Kapa Biosystems, USA), $0.5 \mu \mathrm{L}$ of each primer at a final concentration of $300 \mathrm{nM}$, and $1.5 \mu \mathrm{L}$ of deionized water. The amplification conditions were as follows: $95^{\circ} \mathrm{C}$ for $4 \mathrm{~min}$, followed by 35 cycles of denaturation at $95^{\circ} \mathrm{C}$ for $15 \mathrm{~s}$, annealing of primers at $58^{\circ} \mathrm{C}$ for $20 \mathrm{~s}$ and extension at $72{ }^{\circ} \mathrm{C}$ for $8 \mathrm{~s}$. The negative results were checked by using mammal $\beta$-actin primers (Francino et al., 2006). A standard curve was generated using serial dilutions of $L$. infantum DNA (MHOM/BR/72/strain46) from $0.5 \times 10^{6}$ to $0.5 \times 10^{-4}$ parasites $/ \mu \mathrm{L}$. The amplifications were performed in duplicate and parasite load was obtained by plotting the $\mathrm{Ct}$ values against the standardized parasite concentrations.

\subsection{Statistical analysis}

We used STATA package (version 13.0) for statistical analysis. Normality was evaluated by the D'Agostino Pearson test. The frequencies of positive results found in clinical samples of 92 dogs were compared in pairs by the McNemar's Chi-square test. Differences between clinical groups were analyzed by the twoproportion $z$-test. Parasite loads were compared in pairs using the Mann-Whitney test. Differences were considered significant when $p$ value was $\leq 0.05$.

\section{Results}

\subsection{Percentages of positive qPCR results in different tissues and serology}

Distribution of qPCR results with several samples and serology for the 92 infected dogs is showed in Table 1 . The percentage of positive results was equivalent between OS $(67.4 \%, 62 / 92)$ and CS $(68.5 \%, 63 / 92)(p>0.05)$, and positivity of both noninvasive samples was higher than that found in BL $(52.2 \%, 48 / 92)(p \leq 0.05)$. LN showed higher positivity compared with the other samples $(84.8 \%, 78 / 92)(p \leq 0.05)$ (Table 1$)$. Regarding serology, positivity (78.3\%, 72/92) was equivalent to that found in qPCR-OS, qPCR-CS and qPCR-LN $(p>0.05)$, but higher than qPCR-BL $(p \leq 0.05)$ (Table 1$)$. Between clinical groups, SD dogs showed a significantly higher frequency of positive results than AD dogs in all samples investigated by qPCR $(p \leq 0.05)$, except BL $(p>0.05)$. Positivity was equivalent between OS and LN in SD dogs $(p>0.05)$, but not in the AD population $(p \leq 0.05)$. Serological positive results did not differ between clinical groups $(p>0.05)$ (Fig. 1$)$.
Table 1

Distribution of real time-PCR results and serology for the 92 dogs infected with Leishmania infantum.

\begin{tabular}{|c|c|c|c|c|c|c|}
\hline \multicolumn{2}{|l|}{ Dogs } & \multicolumn{4}{|l|}{ qPCR } & \multirow[t]{2}{*}{ Serology } \\
\hline $\mathrm{N}$ & $\%$ & OS & CS & $\mathrm{BL}$ & LN & \\
\hline 24 & 26.1 & + & + & + & + & + \\
\hline 20 & 21.7 & + & + & - & + & + \\
\hline 7 & 7.6 & - & + & + & + & + \\
\hline 4 & 4.3 & - & - & - & + & - \\
\hline 4 & 4.3 & - & - & - & + & + \\
\hline 4 & 4.3 & - & + & - & + & - \\
\hline 4 & 4.3 & + & - & - & + & + \\
\hline 3 & 3.3 & - & + & - & + & + \\
\hline 3 & 3.3 & - & - & + & - & + \\
\hline 3 & 3.3 & + & - & + & - & + \\
\hline 2 & 2.2 & - & - & + & - & - \\
\hline 2 & 2.2 & - & - & + & + & - \\
\hline 2 & 2.2 & + & - & + & + & + \\
\hline 2 & 2.2 & + & - & - & - & - \\
\hline 1 & 1.1 & - & + & + & + & - \\
\hline 1 & 1.1 & + & - & - & + & - \\
\hline 1 & 1.1 & + & - & + & - & - \\
\hline 1 & 1.1 & + & - & + & + & - \\
\hline 1 & 1.1 & + & + & + & - & + \\
\hline 1 & 1.1 & + & + & - & + & - \\
\hline 1 & 1.1 & + & + & - & - & + \\
\hline 1 & 1.1 & + & + & + & - & - \\
\hline$* \%$ of positivity & & $\begin{array}{l}67.4 \\
(62 / 92)\end{array}$ & $\begin{array}{l}68.5 \\
(63 / 92)\end{array}$ & $\begin{array}{l}52.2 \\
(48 / 92)\end{array}$ & $\begin{array}{l}84.8 \\
(78 / 92)\end{array}$ & $\begin{array}{l}78.3 \\
(72 / 92)\end{array}$ \\
\hline
\end{tabular}

$* \%$ of positivity: $\mathrm{OS} \times \mathrm{CS} p>0.05 ; \mathrm{OS} \times$ Serology $p>0.05 ; \mathrm{LN}>\mathrm{OS}=\mathrm{CS}>\mathrm{BL} p \leq 0.05$.

\subsection{Combining results with oral swab}

Neither qPCR nor serology achieved maximum sensitivity for detecting the infected dogs. Therefore, we combined results in order to increase positivity, focusing the OS results. Considering total population $(n=92)$, all combinations significantly increased $(p \leq 0.05)$ the positivity, compared to results found when OS was used alone (67.4\%), as follows: OS + CS $=83.7 \% ; \quad$ OS + serology $=85.9 \%, \quad$ OS $+C S+$ serology $=91.3 \%$, and $\mathrm{OS}+\mathrm{LN}=94.6 \%$.

For AD dogs that presented very low positivity when OS was used alone (36.7\%), there was a significant increase $(p \leq 0.05)$ when OS was combined with CS (63.4\%), with CS + serology (83.4\%) and with LN (86.7\%) (Fig. 2).

For SD dogs, the OS positivity, already high at $82.3 \%$, increased to $93.6 \%$ when combined with CS, to $95.2 \%$ with CS + serology, and to its maximum value of $98.4 \%$ with LN (Fig. 2)

\subsection{Contribution of OS and CS qPCR for diagnosing seronegative dogs}

Among the 20 infected dogs $(A D=9 ; S D=11)$ that were seronegative, $35 \%(7 / 20)$ were $O S$ positive $(A D=3 / 9, S D=4 / 11), 35 \%(7 / 20)$ were $C S$ positive $(A D=1 / 9 ; S D=6 / 11)$, and $60 \%(12 / 20)$ were $O S$ and/or $C S$ positive $(A D=4 / 9 ; S D=8 / 11)$.

\subsection{Parasite load}

The LN showed higher parasite load than the other clinical samples $(\mathrm{p} \leq 0.05)$. The amount of parasite load was equivalent between noninvasive samples, OS and CS $(p>0.05)$, and both were higher compared to $\mathrm{BL}(p \leq 0.05)$. The median of parasite load per reaction tube in total population $(\mathrm{n}=92)$ was 440.0 (range 1.1 to $1.1 \times$ $10^{6}$ ) in OS, 369.5 (range 2.0 to $2.0 \times 10^{4}$ ) in CS, 153.0 (range 1.9 to $1.0 \times 10^{3}$ ) in BL, and 1419.5 (range 2.7 to $4.89 \times 10^{5}$ ) in LN.

With regard to clinical groups, parasite load was significantly higher in SD dogs in all samples $(p \leq 0.05)$, except in BL where 


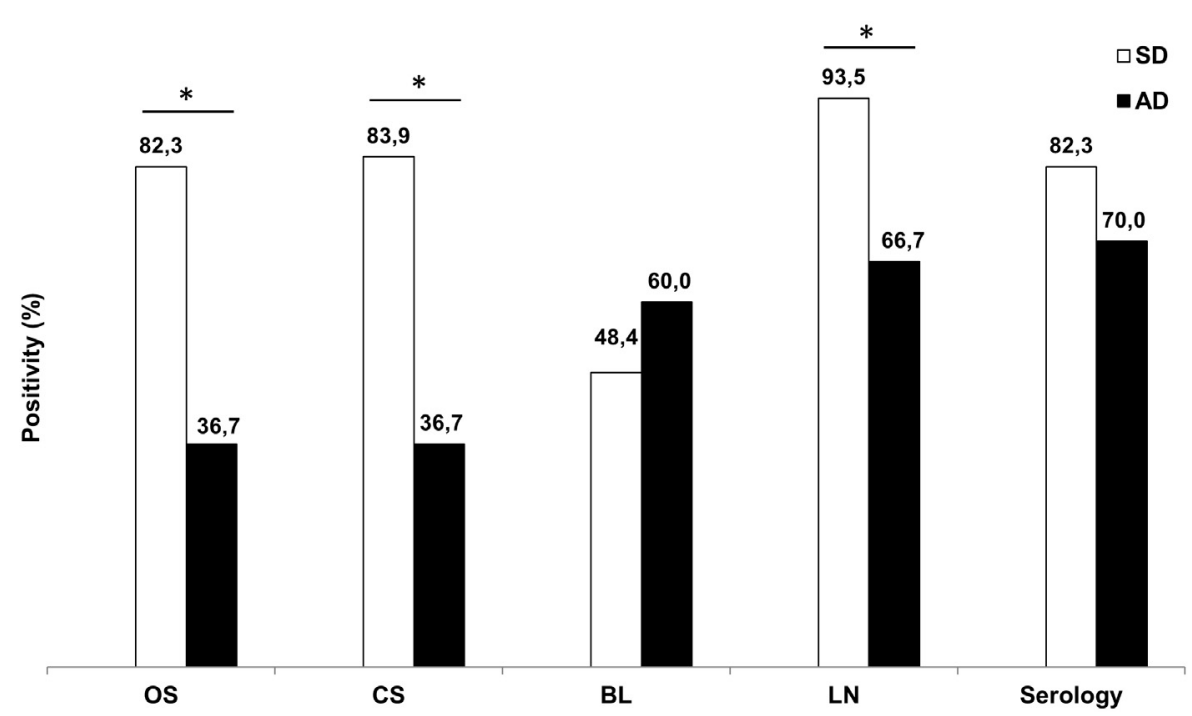

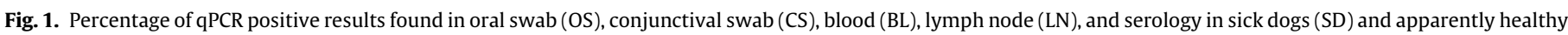
infected dogs (AD) with $L$. infantum.

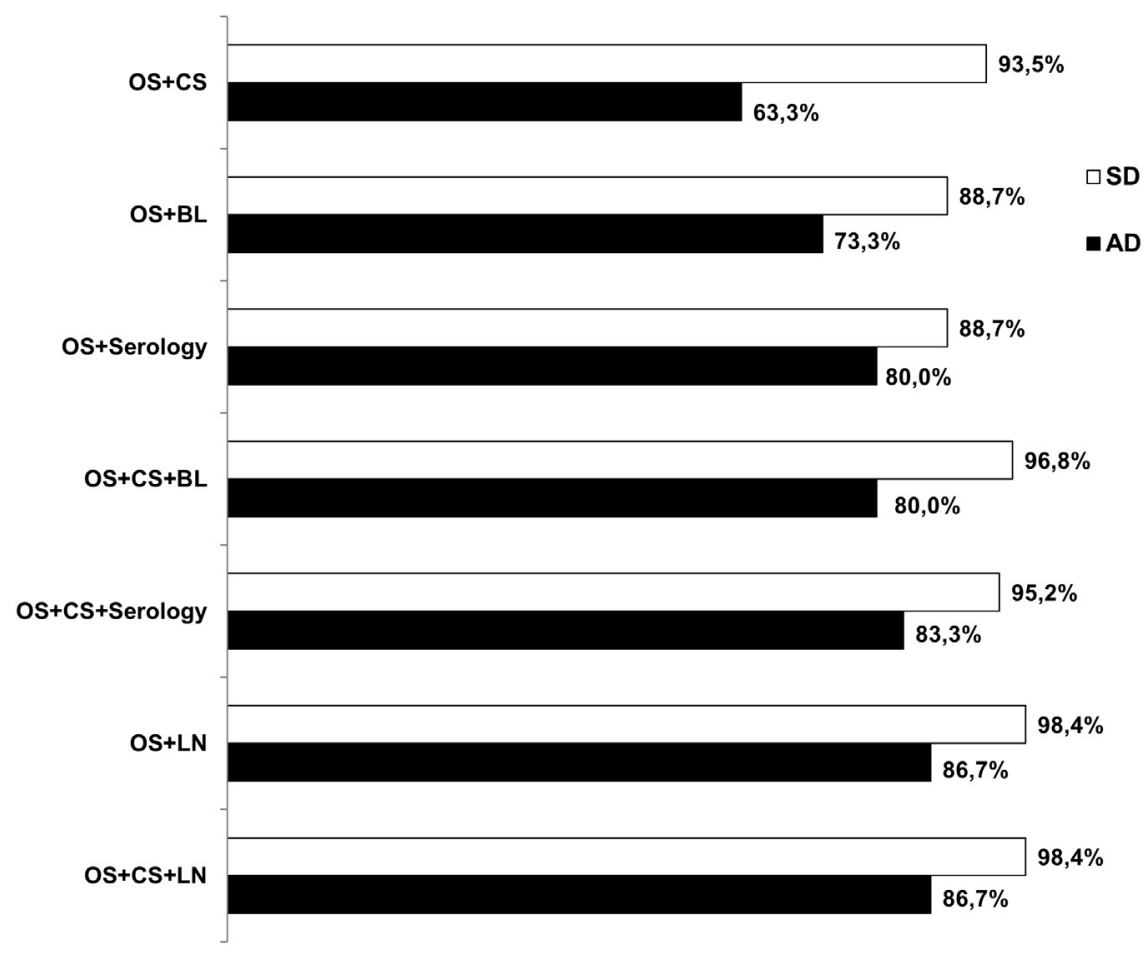

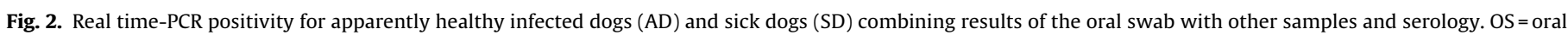
swab; $\mathrm{CS}=$ conjunctival swab, $\mathrm{BL}=$ blood, $\mathrm{LN}=$ lymph node.

the parasitism was equivalent between SD and AD dogs $(p>0.05)$ (Fig. 3).

\section{Discussion}

Control strategies for reducing VL in endemic areas include an accurate and early diagnosis of infected dogs. Aiming to improve the detection of dogs infected with L. infantum, this study employed qPCR on OS samples that can be easily collected in clinics and on a large scale. For comparison, we also evaluated the performance of the CS, BL, LN and serology, considering clinical groups, parasite load, and combination of the OS results with other samples and serology.
The present study demonstrated the presence of Leishmania DNA in the oral cavities of 62 out of 92 dogs studied. The OS positivity (67.4\%) was equivalent to CS (68.5\%) ( $p>0.05)$, higher than $\operatorname{BL}(52.2 \%)(\mathrm{p} \leq 0.05)$, and lower than $\operatorname{LN}(84.8 \%)(\mathrm{p} \leq 0.05)$.

With regard to the clinical groups, positivity of SD dogs was higher than $\mathrm{AD}$ ones in all samples analyzed, except blood. OS proved to be a suitable sample for diagnosing sick dogs because its positivity was high and equivalent to that found in LN; in accordance to another report (de Ferreira et al., 2013). The same was not true for the AD group, since Leishmania DNA was detected in only $37.9 \%$ of them.

The detection of parasites in the oral cavity may have important epidemiological implications since direct contact among dogs, 


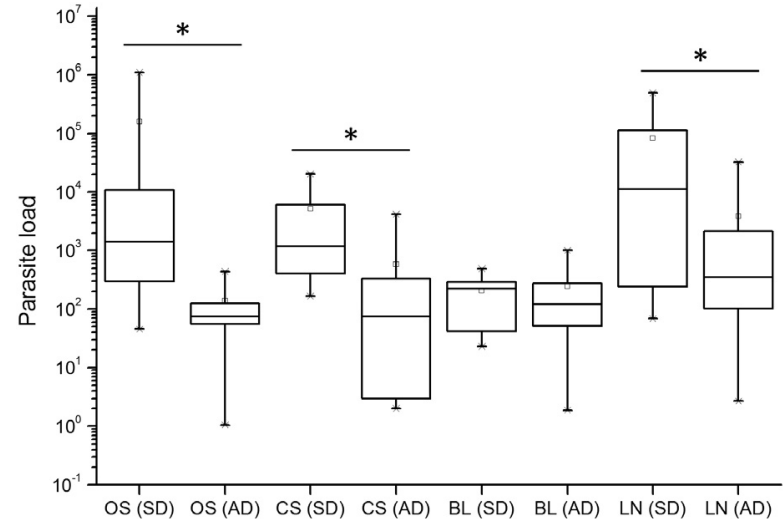

Fig. 3. Box plot graphic representing the parasite load (median, maximum and minimum values) in different tissues of apparently healthy infected dogs (AD) and sick dogs (SD). OS = oral swab; $C S=$ conjunctival swab, $\mathrm{BL}=$ blood, $\mathrm{LN}=$ lymph node.

through saliva or bites, has been implicated in parasite transmission (Schantz et al., 2005; Quinnell and Courtenay, 2009; Lombardo et al., 2012). In the present study, we detected L. infantum in OS of dogs from a municipality (Embu das Artes) where CVL occurs in the absence of the $\mathrm{Lu}$. longipalpis vector, reinforcing the possible dog-to-dog transmission (BEPA, 2011).

Among the noninvasive samples, CS has been the most studied and its use for screening dogs in endemic regions has been suggested (Di Muccio et al., 2012; de Ferreira et al., 2013; Leite et al., 2015). In this study, CS tested positive in $68.5 \%$ of the dogs investigated. This overall positivity was hindered due to the low positivity found in AD dogs (36.7\%), as opposed to the positivity found in SD animals (82.3\%). In other reports, the parasite detection in the conjunctiva of sick dogs ranged from 73.9\% to 95.6\% (Strauss-Ayali et al., 2004; Pilatti et al., 2009; Di Muccio et al., 2012; de Ferreira et al., 2013). Surprisingly, Leite et al. (2010) found $90 \%$ positivity in apparently healthy infected animals, and it is likely that they were at a more advanced infection stage, closer to widespread infection and clinical disease, than the dogs in this study. Reinforcing our hypothesis, a longitudinal study pointed out that parasite detection in CS is not effective in the early stages of canine infection (Gramiccia et al., 2010).

Here, BL showed the lowest Leishmania DNA detection and was the sole sample that yielded equivalent results between $\mathrm{AD}$ and SD dogs $(p>0.05)$. Most studies have reported poor results with BL (Leite et al., 2010; Lombardo et al., 2012), but not all have (Manna et al., 2004). The reasons for these controversial results are due to the fluctuation of parasite load in peripheral blood during the course of infection (Gramiccia et al., 2010). In short, BL is not a suitable sample for diagnostic purposes.

LN gave the highest positivity, an expected result since $L$. infantum has a remarkable tropism for lymphoid tissues, such as lymph nodes, spleen and bone marrow. Previous molecular studies have confirmed high positivity in these sites (Almeida et al., 2013; Ramos et al., 2013). Regarding clinical groups, LN positivity was significantly higher in infected dogs with clinical signs compared to those with inapparent infection, as occurred with noninvasive samples.

The positivity rate found in the qualitative molecular diagnosis was intimately related with the parasite load, since it was high in $\mathrm{LN}$, moderate and equivalent between OS and CS, and low in BL.

Regarding serology, we adopted two tests, in accordance with the Brazilian Ministry of Health, that advocated, by the end of 2011, the exclusion of the immunofluorescence assay and the inclusion of the rapid test DPP ${ }^{\circledR}$ Canine Leishmaniasis (Biomanguinhos/FIOCRUZ/Rio de Janeiro, Brazil) for screening dogs, and the enzyme-immunoassay (EIE- Biomanguinhos/FIOCRUZ/Rio de Janeiro, Brazil) to confirm the positive results. This novel proto- col improved the diagnostic accuracy (Laurenti et al., 2014), and proved that the magnitude of infection in endemic areas was far greater than estimated with the old serological protocol (CouraVital et al., 2014). In the current study, serology provided $78.3 \%$ of the positive results, and detected Leishmania infection in $82.3 \%$ of the SD dogs and in 70\% of the AD dogs, in contrast with another report that found low positivity in apparently healthy infected dogs (Grimaldi et al., 2012).

CVL is a complex disease, and the multiple infection stages of dogs after exposure to L. infantum make diagnosis difficult; therefore, the combination of more than one diagnostic technique has been recommended (Oliva et al., 2006; Solano-Gallego et al., 2011; Morales-Yuste et al., 2012). Serology is the method most used in endemic areas, but some of the infected dogs may never seroconvert to positive (Oliva et al., 2006; Falqueto et al., 2009; Gramiccia et al., 2010), showing the need to combine tests.

PCR is a sensitive tool that can detect infection in seronegative dogs (Quinnell et al., 2001; Gramiccia et al., 2010; Coura-Vital et al., 2013). In the current study, a fraction of the 20 seronegative animals were qPCR-OS (35\%) or qPCR-CS (35\%) positive, and 60\% were qPCR positive when the results of both noninvasive samples were jointly analyzed.

According to the results of this study, OS performed well for SD dogs and presented comparable results to LN, but not for AD animals, and sampling combination must be considered for increasing positivity. For them, we suggest using the combination of OS with CS or the combination of both samples with serology, since this resulted in a significant increase in positivity. For reducing time and cost and to enhance diagnostic sensitivity, both noninvasive swabs could be processed as one sample, as already suggested by others (de Ferreira et al., 2013). Although to a lesser extent, combined results also increased positivity in the SD population, reaching up to $95.2 \%$, using the aforementioned combinations.

In conclusion, OS showed a high potential for the molecular diagnosis of sick dogs. Conversely, OS showed low sensitivity for detecting apparently healthy infected dogs, and we recommend its combination with CS and/or serology for reaching relevant $L$. infantum detection. Another advantage of using OS or both noninvasive samples is the increased likelihood of diagnosing seronegative dogs. Finally, our findings clearly showed that combining tests and/or samples is required for identifying most of the dogs naturally infected with L. infantum, and that the OS, along with the CS, based on PCR assays, can significantly contribute for detecting dogs in different stages of the infection.

\section{Conflict of interest}

The authors declare there are no conflicts of interest.

\section{Acknowledgments}

This project was supported by grants \# 2009/54533-4 and \# 2011/09331-4 from the São Paulo Research Foundation and LIM50 HC-FMUSP.

\section{References}

Almeida, A.B.P.F., Sousa, V.R.F., Gasparetto, N.D., Da Silva, G.F.R., Figueiredo, F.B., Dutra, V., Nakazato, L., Madeira, M.F., 2013. Canine visceral leishmaniasis: diagnostic approaches based on polymerase chain reaction employing different biological samples. Diagn. Microbiol. Infect. Dis. 76, 321-324.

Alvar, J., Vélez, I.D., Bern, C., Herrero, M., Desjeux, P., Cano, J., Jannin, J., den Boer, M., 2012. Leishmaniasis worldwide and global estimates of its incidence. PLoS One 7, e35671.

BEPA, 2011. Boletim Epidemiológico Paulista: Secretaria de Estado da Saúde de São Paulo. Classificação epidemiológica dos municípios segundo o Programa de Vigilância e Controle da Leishmaniose Visceral Americana no Estado de São Paulo. São Paulo, 8 (96), 32-33. 
Bevilacqua, P.D., Alves, W.A., 2004. Reflexões sobre a qualidade do diagnóstico da leishmaniose visceral canina em inquéritos epidemiológicos: o caso da epidemia de Belo Horizonte, Minas Gerais, Brasil, 1993-1997. Cad. Saude Publica 20, 259-265.

Coura-Vital, W., Reis, A.B., Fausto, M.A., Leal, G.G.D.A., Marques, M.J., Veloso, V.M., Carneiro, M., 2013. Risk factors for seroconversion by Leishmania infantum in a cohort of dogs from an endemic area of Brazil. PLoS One 8, e71833.

Coura-Vital, W., Ker, H.G., Roatt, B.M., Aguiar-Soares, R.D.O., Leal, G.G.D.A., Moreira, N.D.D., Oliveira, L.A.M., Machado, E.M.D.M., Morais, M.H.F., Corrêa-Oliveira, R., Carneiro, M., Reis, A.B., 2014. Evaluation of change in canine diagnosis protocol adopted by the visceral leishmaniasis control program in Brazil and a new proposal for diagnosis. PLoS One 9, 1-6.

Di Muccio, T., Veronesi, F., Antognoni, M.T., Onofri, A., Piergili Fioretti, D. Gramiccia, M., 2012. Diagnostic value of conjunctival swab sampling associated with nested PCR for different categories of dogs naturally exposed to Leishmania infantum infection. J. Clin. Microbiol. 50 (8), 2651-2659.

Falqueto, A., Ferreira, A.L., dos Santos, C.B., Porrozzi, R., da Costa, M.V., Teva, A., Cupolillo, E., Campos-Neto, A., Grimaldi, G., 2009. Cross-sectional and longitudinal epidemiologic surveys of human and canine Leishmania infantum visceral infections in an endemic rural area of southeast Brazil (Pancas Espirito Santo). Am. J. Trop. Med. Hyg. 280, 559-565.

Francino, O., Altet, L., Sánchez-Robert, E., Rodriguez, A., Solano-Gallego, L., Alberola, J., Ferrer, L., Sánchez, A., Roura, X., 2006. Advantages of real-time PCR assay for diagnosis and monitoring of canine leishmaniosis. Vet. Parasitol. 137, 214-221.

Gomes, Y.M., Paiva Cavalcanti, M., Lira, R.A., Abath, F.G.C., Alves, L.C., 2008. Diagnosis of canine visceral leishmaniasis: biotechnological advances. Vet. J. $175,45-52$

Gramiccia, M., Di Muccio, T., Fiorentino, E., Scalone, A., Bongiorno, G., Cappiello, S. Paparcone, R., Manzillo, V.F., Maroli, M., Gradoni, L., Oliva, G., 2010. Longitudinal study on the detection of canine Leishmania infections by conjunctival swab analysis and correlation with entomological parameters. Vet. Parasitol. 171, 223-228.

Grimaldi, G., Tesh, R.B., 1993. Leishmaniases of the New World: current concepts and implications for future research. Clin. Microbiol. Rev. 6, 230-250.

Grimaldi, G., Teva, A., Ferreira, A.L., dos Santos, C.B., de Pinto, I.-S., de-Azevedo, C.T. Falqueto, A., 2012. Evaluation of a novel chromatographic immunoassay based on dual-path platform technology (DPP ${ }^{\circledR}$ CVL rapid test) for the serodiagnosis of canine visceral leishmaniasis. Trans. R. Soc. Trop. Med. Hyg. 106, 54-59.

Laranjeira, D.F., Matta, V.L.R., Da Tomokane, T.Y., Marcondes, M., Corbet, C.E.P., Laurenti, M.D., 2014. Serological and infection statuses of dogs from a visceral leishmaniasis-endemic area. Rev. Saude Publica 48, 563-571.

Laurenti, M.D., Rossi, C.N., da Matta, V.L.R., Tomokane, T.Y., Corbett, C.E.P., Secundino, N.F.C., Pimenta, P.F.P., Marcondes, M., 2013. Asymptomatic dogs are highly competent to transmit Leishmania (Leishmania) infantum chagasi to the natural vector. Vet. Parasitol. 196, 296-300.

Laurenti, M.D., de Santana Leandro, M.V., Tomokane, T.Y., De Lucca, H.R.L., Aschar, M., Souza, C.S.F., Silva, R.M., Marcondes, M., da Matta, V.L.R., 2014. Comparative evaluation of the DPP $\left({ }^{\circledR}\right)$ CVL rapid test for canine serodiagnosis in area of visceral leishmaniasis. Vet. Parasitol. 205, 444-450.

Leite, R.S., de Ferreira, S.A., Ituassu, L.T., de Melo, M.N., de Andrade, A.S.R., 2010 PCR diagnosis of visceral leishmaniasis in asymptomatic dogs using conjunctival swab samples. Vet. Parasitol. 170, 201-206.

Leite, R.S., Souza, N.A., Barbosa, A.D., Ferreira, A.L.C., de Andrade, A.S.R., 2015. Evaluation of conjunctival swab as a mass-screening tool for molecular diagnosis of canine visceral leishmaniasis. Parasitol. Res., 2255-2262.

Lombardo, G., Pennisi, M.G., Lupo, T., Migliazzo, A., Caprì, A., Solano-Gallego, L., 2012. Detection of Leishmania infantum DNA by real-time PCR in canine oral and conjunctival swabs and comparison with other diagnostic techniques. Vet. Parasitol. 184, 10-17

Manna, L., Vitale, F., Reale, S., Caracappa, S., Pavone, L.M., Morte, R., Della Cringoli, G., Staiano, N., Gravino, A.E., 2004. Comparison of different tissue sampling for PCR-based diagnosis and follow-up of canine visceral leishmaniosis. Vet. Parasitol. 125, 251-262.

Marcondes, M., de Lima, V.M.F., de Araújo, M.D.F.L., Hiramoto, R.M., Tolezano, J.E., Vieira, R.F.C., Biondo, A.W., 2013. Longitudinal analysis of serological tests officially adopted by the Brazilian Ministry of Health for the diagnosis of canine visceral leishmaniasis in dogs vaccinated with Leishmune $\left.{ }^{\circledR}\right)$. Vet. Parasitol. 197, 649-652.

Michalsky, E.M., Rocha, M.F., da Rocha Lima, A.C.V.M., França-Silva, J.C., Pires, M.Q. Oliveira, F.S., Pacheco, R.S., dos Santos, S.L., Barata, R.A., Romanha, A.J., Fortes-Dias, C.L., Dias, E.S., 2007. Infectivity of seropositive dogs, showing different clinical forms of leishmaniasis, to Lutzomyia longipalpis phlebotomine sand flies. Vet. Parasitol. 147, 67-76.

Miró, G., Cardoso, L., Pennisi, M.G., Oliva, G., Baneth, G., 2008. Canine leishmaniosis-new concepts and insights on an expanding zoonosis: part two. Trends Parasitol. 24, 371-377.

Morales-Yuste, M., Morillas-Márquez, F., Díaz-Sáez, V., Barón-López, S., Acedo-Sánchez, C., Martín-Sánchez, J., 2012. Epidemiological implications of the use of various methods for the diagnosis of canine leishmaniasis in dogs with different characteristics and in differing prevalence scenarios. Parasitol. Res. 111, 155-164.

Moreira, M.A.B., Luvizotto, M.C.R., Garcia, J.F., Corbett, C.E.P., Laurenti, M.D., 2007. Comparison of parasitological: immunological and molecular methods for the diagnosis of leishmaniasis in dogs with different clinical signs. Vet. Parasitol. $145,245-252$.
Oliva, G., Scalone, A., Manzillo, V.F., Gramiccia, M., Pagano, A., Muccio, T., Di Gradoni, L., 2006. Incidence and time course of Leishmania infantum infections examined by parasitological, serologic, and nested-PCR techniques in a cohort of Naıve dogs exposed to three consecutive transmission seasons. J. Clin. Microbiol. 44, 1318-1322.

Pilatti, M.M., Ferreira, S.D.A., de Melo, M.N., de Andrade, A.S.R., 2009. Comparison of PCR methods for diagnosis of canine visceral leishmaniasis in conjunctival swab samples. Res. Vet. Sci. 87, 255-257.

Porrozzi, R., Santos da Costa, M.V., Teva, A., Falqueto, A., Ferreira, A.L., dos Santos, C.D., Fernandes, A.P., Gazzinelli, R.T., Campos-Neto, A., Grimaldi, G., 2007 Comparative evaluation of enzyme-linked immunosorbent assays based on crude and recombinant leishmanial antigens for serodiagnosis of symptomatic and asymptomatic Leishmania infantum visceral infections in dogs. Clin. Vaccine Immunol. 14, 544-548.

Quaresma, P.F., Murta, S.M.F., de Castro Ferreira, E., da Rocha-Lima, C.V.M., Xavier, a.P., Gontijo, C.M.F., 2009. Molecular diagnosis of canine visceral leishmaniasis: identification of Leishmania species by PCR-RFLP and quantification of parasite DNA by real-time PCR. Acta Trop. 111, 289-294.

Quinnell, R.J., Courtenay, O., 2009. Transmission, reservoir hosts and control of zoonotic visceral leishmaniasis. Parasitology 136, 1915.

Quinnell, R.J., Courtenay, O., Davidson, S., Garcez, L., Lambson, B., 2001. Detection of Leishmania infantum by PCR: serology and cellular immune response in a cohort study of Brazilian dogs. Parasitology 122, 253-261.

Ramos, R.A.N., Ramos, C.A.d.N., Santos, E.M.d.S., Araujo, F.R.d., Carvalho, G.A.d., Faustino, M.A.d.G., Alves, L.C., 2013. Quantification of Leishmania infantum DNA in the bone marrow, lymph node and spleen of dogs. Rev. Bras. Parasitol. Vet. 22, 346-350.

Reis, L.E.S., Coura-Vital, W., Roatt, B.M., Bouillet É, L.M., Ker, H.G., Fortes de Brito, R.C., de Resende, D.M., Carneiro, M., Giunchetti, R.C., Marques, M.J., Carneiro, C.M., Reis, A.B., 2013. Molecular diagnosis of canine visceral leishmaniasis: a comparative study of three methods using skin and spleen from dogs with natural Leishmania infantum infection. Vet. Parasitol. 197, 498-503.

Romero, G.A., Boelaert, M., 2010. Control of visceral leishmaniasis in Latin America-a systematic review. PLoS Negl. Trop. Dis. 4 (1), e584.

Santos, T.R., Carreira, V.S., Ferrari, H.F., Moreira, M.A.B., Luvizotto, M.C.R., 2014. Comparison of PCR with stained slides of bone marrow and lymph nodes aspirates with suspect diagnosis for leishmaniasis. Acta Trop. 140, 137-140.

Schantz, P.M., Steurer, F.J., Duprey, Z.H., Kurpel, K.P., Barr, S.C., Jackson, J.E., Breitschwerdt, E.B., Levy, M.G., Fox, J.C., 2005. Autochthonous visceral leishmaniasis in dogs in North America. J. Am. Vet. Med. Assoc. 226 (8), 1316-1322.

Solano-Gallego, L., Miró, G., Koutinas, A., Cardoso, L., Pennisi, M.G., Ferrer, L., Bourdeau, P., Oliva, G., Baneth, G., 2011. The Leish Vet Group. LeishVet guidelines for the practical management of canine leishmaniosis. Parasite Vectors 4, 86

Srividya, G., Kulshrestha, A., Singh, R., Salotra, P., 2012. Diagnosis of visceral leishmaniasis: developments over the last decade. Parasitol. Res. 110, 1065-1078.

Strauss-Ayali, D., Jaffe, C.L., Burshtain, O., Gonen, L., Baneth, G., 2004. Polymerase chain reaction using noninvasively obtained samples, for the detection of Leishmania infantum DNA in dogs. J. Infect. Dis. 189, 1729-1733.

WHO, World Health Organization, 2011. Control of the leishmaniases. World Health Organ Tech Rep Ser. 2010. 949, 1-186.

Werneck, G.L., Costa, C.H., Walker, A.M., David, J.R., Wand, M., Maguire, J.H., 2007. Multilevel modelling of the incidence of visceral leishmaniasis in Teresina. Brazil. Epidemiol. Infect. 135, 195-201.

Xavier, S.C., De Andrade, H.M., Jamil, S., Monte, H., Chiarelli, I.M., Lima, W.G., Suzan, M., Michalick, M., Tafuri, W.L., Tafuri, W.L., 2006. Comparison of paraffin-embedded skin biopsies from different anatomical regions as sampling methods for detection of Leishmania infection in dogs using histological, immunohistochemical and PCR methods. BMC Vet. Res. 2, 17.

Zanette, M.F., de Lima, V.M.F., Laurenti, M.D., Rossi, C.N., Vides, J.P., Vieira, R.F.D.C., Biondo, A.W., Marcondes, M., 2014. Serological cross-reactivity of Trypanosoma cruzi Ehrlichia canis, Toxoplasma gondii, Neospora caninum and Babesia canis to Leishmania infantum chagasi tests in dogs. Rev. Soc. Bras. Med. Trop. 47, 105-107

de Almeida Ferreira, S., Leite, R.S., Ituassu, L.T., Almeida, G.G., Souza, D.M., Fujiwara, R.T., de Andrade, A.S.R., Melo, M.N., 2012. Canine skin and conjunctival swab samples for the detection and quantification of Leishmania infantum DNA in an endemic urban area in Brazil. PLoS Negl. Trop. Dis. 6, 1-9.

de Ferreira, S.A., Almeida, G.G., de Silva, S.O., Vogas, G.P., Fujiwara, R.T., de Andrade, A.S.R., Melo, M.N., 2013. Nasal, oral and ear swabs for canine visceral leishmaniasis diagnosis: new practical approaches for detection of Leishmania infantum DNA. PLoS Negl. Trop. Dis. 7, 1-8.

de Paiva Cavalcanti, M., Felinto de Brito, M.E., de Souza, W.V., de Miranda Gomes, Y., Abath, F.G.C., 2009. The development of a real-time PCR assay for the quantification of Leishmania infantum DNA in canine blood. Vet. J. 182, 356-358.

do Rosário, E.Y., Genaro, O., França-Silva, J.C., Da Costa, R.T., Mayrink, W., Reis, A.B., Carneiro, M., 2005. Evaluation of enzyme-linked immunosorbent assay using crude Leishmania and recombinant antigens as a diagnostic marker for canine visceral leishmaniasis. Mem. Inst. Oswaldo Cruz 100, 197-203. 